\title{
CONTRASTE, EMBATE E VONTADE EM O RETORNO, DE DULCE MARIA CARDOSO
}

\author{
Sabrina Sedlmayer ${ }^{1}$
}

Guilherme Ribeiro $^{2}$

\begin{abstract}
RESUMO: Partindo de estudos sobre a agonia, sentimento desassossegado que (des)articula desejo e escolha, este ensaio propõe uma linha argumentativa que relaciona a reinvenção da identidade pessoal dentro de uma complexa situação histórica. Para tanto, aproxima-se da voz do narrador do romance O Retorno (2012), de Dulce Maria Cardoso, para explorar as polaridades que marcam as migrações portuguesas não voluntárias dentro do processo histórico que transformou colonos em retornados. A descolonização dos antigos territórios portugueses em África, a chegada de uma família específica em Lisboa e as reflexões do adolescente Rui servem como base para as análises que tratarão da luta que se dá, nessa narrativa, entre polos díspares: brancos e negros; Luanda e Lisboa; retornados e portugueses; cordialidade idílica e mito luso-tropicalista; discurso paterno e discurso revolucionário, entre outros, numa densa rede de embate, na qual se encena a vontade humana de deixar rastros e de sobreviver.
\end{abstract}

PALAVRAS-CHAVE: Agonia. Retornados. Descolonização portuguesa. Dulce Maria Cardoso.

\section{CONTRAST, CLASHING AND WILL IN O RETORNO, BY DULCE MARIA CARDOSO}

\begin{abstract}
Starting from the Greek concept of agony, the restless feeling that (dis)articulates desire and choice, this essay proposes an argumentative line of thought that relates the reinvention of personal identity inside a complex historical situation. For that end, an approach is taken to the voice of the narrator of the 2012 romance O Retorno, written by Dulce Maria Cardoso, so as to explore the polarities that marked the non-voluntary Portuguese migrations inside the very historical process that transformed colonial settlers into the "returned". The decolonization of the old Portuguese territories in Africa, the arrival of a specific family in Lisbon and the reflections of teenager Rui serve as a base for the analyses that will deal with the struggle that is presented, in this narrative, between disparate polar opposites: black and white; Luanda and Lisbon; "returned" and Portuguese, idyllic cordiality and the luso-tropicalist myth; paternal speech and revolutionary discourse, among others in a dense web of clashing discussion in which the human volition to survive and leave a mark is staged.
\end{abstract}

KEY-WORDS: Agony. Portuguese decolonization. Returned. Dulce Maria Cardoso.

\section{O preto no branco}

Um problema que atravessa toda a enunciação empreendida pelo jovem angolano Rui, no romance O Retorno, de Dulce Maria Cardoso (2013), é a agonística que reveste as relações pessoais e coletivas após o 25 de abril de 1974, mas não é como se a beligerância surja somente após a Revolução dos Cravos. A hipótese levantada neste ensaio é a de que

\footnotetext{
${ }^{1}$ Sabrina Sedlmayer é professora Associada II da Faculdade de Letras da Universidade Federal de Minas Gerais.

${ }^{2}$ Guilherme Ribeiro é graduando em Letras na Universidade Federal de Minas Gerais.
} 
há uma tensa disputa, um acirramento entre perspectivas que põem em xeque não apenas questões políticas e econômicas, mas, principalmente, ideológicas e emocionais. Entre brancos e negros, experiência e memória, desejo de permanência e anseio de fuga, pensamento e ação, liberdade e poder, transgressão moral e anseio ético, há uma densa retensão que sustenta as polaridades da narrativa e que movimenta, agudamente, o espaço familiar que é atingido, de chofre, pela contingência histórica.

O termo ḋ $\gamma \omega v i a$, no grego antigo - que é derivado de $\alpha \gamma \omega \dot{\omega} v$ e que se tornou 'agonia' em português -, de um modo geral, pode ser articulado entre a esfera do combate, do embate e da vontade. Apesar de, em sua origem, ter designado concretamente a luta nos jogos olímpicos e o exercício ginástico, ainda naquela língua, passou a significar, figuradamente, essa luta interior e subjetiva por nós chamada 'angústia', 'ansiedade' ou 'inquietude' - e que mantém relações sempre ambíguas com o desejo e com a escolha. A agonia, portanto, designa sempre uma oposição, um enfrentamento, seja da ordem da interioridade ou da exterioridade ${ }^{3}$. É sempre um estar contra si mesmo ou um estar contra o outro ${ }^{4}$.

É justamente nesse emaranhado, rede de visões de mundo díspares, cujo embate é denso e descortina, sem minimizar, as consequências imediatas do encerramento das atividades da expansão neocolonialista portuguesa em África, que se faz com que o livro de Cardoso traga, ao leitor, mais do que uma história de uma família de retornados ${ }^{5}$. Se nada é pacífico, se não há consenso nem no lugar de onde se partiu, Luanda, nem no lugar aonde

\footnotetext{
${ }^{3}$ Nesse sentido, há outra acepção reveladora, própria do campo da medicina, em que 'agonia' é considerada sinônimo de 'estertor', ambas denotando a "respiração ruidosa dos moribundos" (HOUAISS; VILLAR, 2009, p.833). Aí, na figura do moribundo, é o corpo que está no limiar da presença e que luta consigo mesmo. Podemos mesmo pensar na respiração como o gesto corporal do desejo de permanência e de adiamento e no ruído como o campo sensível e simbólico do enfrentamento entre vida e morte. De toda forma, nesse espaço sígnico da luta, do embate.

4 Segundo Bailly (2000, p.21), os significados podem se tratar de uma "lutte dans les jeux", "exercice gymnastique","exercice en gen.", "lutte en gen." e "agitation de l'âme, inquiétude, anxiété, angoisse". Vale lembrar, a propósito, a trova exemplar de Sá de Miranda (1989, p.57) que, ainda no século XVI, anunciava esse sentimento (mote da representação da subjetividade moderna) em termos de luta interior: "Comigo me desavim/Sou posto todo em perigo;/ Não posso viver comigo/ Não posso fugir de mim". No presente texto, utilizaremos agônico e agonística de forma abrangente e larga conceitualmente, como espécie de sinônimo de desassossego, uma vez que o que se pretende marcar é mais a dinâmica, o movimento dos embates no enunciado e na enunciação no referido romance português do que propriamente $o$ desenvolvimento teórico do termo.

${ }^{5}$ Meio milhão de pessoas foram conduzidas a se integrar à sociedade portuguesa no período que compreende o verão de 1974 ao verão de 1975. Conferir: https://www.publico.pt/temas/jornal/retornados-uma-historiade-sucesso-por-contar-28145408. Como será desenvolvido, a ficção de Dulce Maria Cardoso vai na contramão do discurso que ressalta somente o sucesso, a excepcionalidade e a generosidade portuguesa durante o processo de retorno à Metrópole.
} 
se chegou, Lisboa, através das reminiscências, associações caras ao adolescente-narrador (devido à faixa etária, ele também é um exemplo de cisão entre a criança que foi e o adulto que necessariamente deverá se tornar), percebe-se que, mesmo antes da partida, a agonística já estava claramente exposta, como podemos observar nesse excerto:

O pai nunca fala de revolução, é natural que o livro da vida não tenha nada de sobre revoluções porque são raras as vidas que assistem a uma revolução. O professor de português dizia que tínhamos muita sorte, estávamos a fazer revolução, a gloriosa manhã de abril tinha sido só o princípio, os quarenta e oito anos da noite mais infame tinham chegado ao fim e agora faltava cumprir abril e cumprir abril era descolonizar, democratizar e desenvolver (CARDOSO, 2013, p.46).

Mário, o pai provedor, que ama o lugar que lhe dá trabalho, a terra onde tudo que semeia nasce, que não viajou pelo mundo nem estudou, acreditava que 1975 seria o melhor ano da sua vida e da sua família, composta por Glória, a esposa, por Milucha, a filha mais velha, e por Rui, o filho caçula. O pai, que não era capaz, na visão do filho, "de matar mulheres e crianças mesmo que sejam pretas" (CARDOSO, 2013, p.79), figura o colono adaptado que consegue, de certa forma, viver com os "povos de cor". A cordialidade idílica lusitana a princípio tem, nesse personagem, o exemplo da superioridade do homem branco europeu, aquele que, no território colonial, expandiu o capital financeiro e que via os "pretos" como atrasados tanto do ponto de vista cultural quanto tecnológico. Após o embate tenso com os soldados angolanos que o levaram, com o pretexto de que era o "carniceiro de Grafanil", ele forçosamente terá de rever suas crenças e seus princípios e de alterar a sua visão acerca dos acontecimentos históricos.

Já o professor de português de Rui, citado exatamente no mesmo parágrafo que acabamos de evocar, é a antítese do discurso paterno, pois é aquele que aprendeu a língua do outro, que canta a música do outro e que comemora a saída do branco em terras africanas com euforia:

O professor de português era novo, usava o cabelo comprido e cheirava a liamba, levava viola para as aulas e punha-se a cantar o Monangambé de forma tão sentida como se fosse um preto, naquela roça grande, não tem chuva, é o suor do meu rosto que rasga as plantações, naquela roça grande tem café maduro, e aquele vermelho-cereja são gotas do meu sangue feitas seivas, não cantava bem mas era melhor ouvi-lo desafinar o Monangambé ou o Mon'etu ua Kassule akutumissa ku San Tomé do que estudar os cantos dos Lusíadas. $\mathrm{O}$ professor de português da turma $\mathrm{B}$ queimou os Lusíadas, o império não devia ter existido e os Lusíadas que o aclamam também não (CARDOSO, 2013, p.46). 


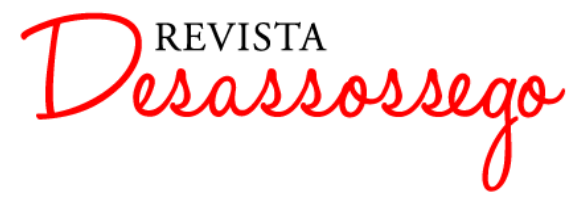

A revolução versus a tradição surge, assim, via Os Lusíadas, que, nessa altura, é o hino imperialista cujas glórias e feitos devastaram a Ásia e a África, versos que jamais deveriam ter sido cantados. Em sala de aula, diferente do espaço doméstico, o professor de português entoa o Monangambé numa clara oposição ao cânone literário fortalecido pelos românticos e pelo seu culto de amor nacionalista-ufanista. Tais posições díspares são capazes de apontar o multifacetado mundo em que Rui vivia ainda em Luanda e de antecipar, de certa forma, o que experimentará em sua "viagem iniciática" ${ }^{6}$, seu exílio involuntário, em Lisboa.

A vivência de cada um dos personagens, na metrópole, desconstrói o mito lusotropicalista, como argutamente observa Ana Paula Arnaut numa análise comparativista entre os personagens de O Retorno e Caderno de Memórias Coloniais (2015), de Isabela Figueiredo:

\begin{abstract}
Muitas vezes discriminados pelas famílias, discriminados num país sem condições para os receber mas que também é o deles e olhados de lado por alguns que consideravam que eles vinham "roubar o pouco que é da gente", os retornados (os "entornados", como eram conhecidos) pagam na moeda possível, distanciando-se e criando uma imagem disfórica dos portugueses e de Portugal. Esta funciona sempre em contraste com a recordação de uma terra que já não sendo embora deles e que parecendo cada vez mais irremediavelmente perdida, continua, no entanto, a ser sempre feérica, "inflamante", "sensual e livre" (ARNAUT, 2013, p.107).
\end{abstract}

Portugal, antes da partida, era um lugar no mapa, idealizado, lugar de moças bonitas com brinco de cerejas. Após a chegada, promovia dolorosamente a transformação do colono em retornado. A confusão dos afetos, os confrontos de hábitos e de crenças, as diferenças na tonalidade da pele, as diversas visões acerca da violência e da sexualidade serão a mola propulsora desse romance de Dulce Maria Cardoso, cuja agonística passaremos a demonstrar, a seguir, com mais acuidade.

\title{
II. Migrações agônicas
}

Para aproximar-se daquilo que Eduardo Lourenço adverte, "a maior miséria do colonialismo é que ele coloniza os colonizadores" (LOURENÇO, 2014, p.31), é preciso pensar a partir das bordas, dos limites de um centro irradiador que é, no romance, o

\footnotetext{
${ }^{6}$ Expressão criada por Helder Macedo justamente para apontar como Camões, poeta moderno, fez testemunho da sociedade em que viveu, atravessou o limiar entre Oriente e Ocidente e elaborou um modelo iniciático: transformou a história em criação, um presente degradado num futuro regenerado. (MACEDO, 2013, p. 47-83).
} 
personagem principal, Rui, e de suas imagens que estão em algum lugar entre o passado e o presente. Somente por sua fragmentada e confusa visão (que, à medida que amadurece, passa a ser reflexão) que temos acesso ao mundo interior e exterior que descreverá. E é ela que nos permite redimensionar toda a rede afetiva, psicológica e social que se forma com o desterro e com o realocar-se. A narrativa arqueia-se entre estas duas localizações geográficas precisas: Angola e Portugal, enquanto os movimentos que a formam transitam sempre entre o bruto real e o inflado imaginário, que são, ao mesmo tempo, opostos e complementares.

Mas esse aparente paradoxo parece existir porque na narrativa atua constantemente uma espécie de vontade que pode ser definida, sobretudo, como agônica. Aí a volição tem, em relação à escolha, uma projetividade continuamente tensa, na qual o tempo futuro pode ser dado como resistência ou passividade, como negatividade ou positividade, mas sobretudo na dinâmica do enfrentamento.

Jean-Pierre Vernant, num ensaio sobre a vontade na tragédia grega, busca aproximarse da noção moderna de vontade, a fim de diferenciá-la daquela dos gregos. A citação, aqui, interessa em função do modo como se pode opor àquela outra forma de vontade que procuramos entrever:

A categoria da vontade, no homem de hoje, não supõe apenas uma orientação da pessoa em direção da ação (...), mas, muito mais, uma preeminência que, na ação, se atribui ao agente, ao sujeito humano como origem, causa produtora de todos os atos que dele emanam. $\mathrm{O}$ agente apreende-se a si mesmo, nas suas relações com outrem e com a natureza, como um centro de decisão, como detentor de um poder que não depende nem da afetividade, nem da pura inteligência: poder sui generis do qual Descartes chega a dizer que é infinito, 'em nós tal qual em Deus', porque, em contraste com o entendimento que nas criaturas é necessariamente limitado, o poder da vontade não comporta o mais e o menos; como o livre arbítrio do qual, segundo Descartes, ela é a face psicológica, nós o possuímos inteiro a partir do momento em que o possuímos. A vontade, com efeito, se apresenta como esse poder - que não admite divisão - de dizer sim ou de dizer não, de aquiescer ou de recusar (VERNANT, 2014, p.25-26).

O romance, como já salientado, é montado sob o ponto de vista psicológico. E tal visão moderna idealista da vontade parece-nos insuficiente. Se, de fato, o "poder de dizer sim ou de dizer não" é mesmo indivisível, a escolha, todavia, não se dá num vácuo de espaço e de tempo em que todas as situações se apresentam diante do agente, do personagem principal. Ela acaba condicionada por elementos e por fluxos exteriores, mas 
que também compõem e que formatam a sua subjetividade. Desse modo, condicionada por um tempo histórico demasiado, por fluxos, por processos e por transformações, é que a vontade aqui está fraturada entre escolhas e consciência, exterior e interior. Da parte do personagem, não se vê uma livre irresponsabilidade consciente, nem uma hiperconsciência analítica. Seu agir é sempre tateante, num claro-escuro em que muitas vezes a questão da responsabilidade se dissimula ou é dissimulada.

A narrativa procura dar a ver as formas da agonia durante o intenso processo de mudanças históricas em que se encena a migração à força. Mas a visão do leitor permanece restrita, próxima da voz do personagem principal, em primeira pessoa. Tal bloco discursivo é pontuado aqui e ali por vozes de outras personagens, compreendidas na e pela perspectiva de Rui, justapostas, sem a distinção gráfica costumeira, indicadas no texto tão somente entre vírgulas, em fluxo. Porém, apesar de restritos à visão de Rui, os outros personagens formam um painel múltiplo, dialógico, não se conformando de imediato à posição do narrador, que, à medida que se coloca em xeque diante dos fatos, torna-se mais e mais inseguro e indeciso, chegando ao paroxismo quando afirma, no final do romance: "acho que nunca vou ser capaz de pensar e sentir uma coisa de cada vez" (CARDOSO, 2013, p.267). Aquilo a que se assiste, portanto, é um percurso de complexificação, de questionamento e, num certo sentido, de (des-)aprendizado rumo justamente à maturidade. O que o arrasta é o contexto, a experiência ou, no dizer da diretora do hotel onde a família se hospeda, os "tempos conturbados" (CARDOSO, 2013, p.67).

As primeiras páginas do romance, assim, transcorrem numa temporalidade turva. $\mathrm{O}$ tempo estacado da espera, da escolha entre o que fica e o que se perde, da lembrança de cenas familiares felizes entremeadas a um imaginário prospectivo do desejo. A última vez em que Rui e seus dois amigos, Lee e Gégé, estiveram juntos (CARDOSO, 2013, p.45), aquela em que andara de bicicleta só com Lee, pois Gégé já havia fugido de Angola (CARDOSO, 2013, p. 46-47) ou aquela em que Rui beijara Paula a quem ele queria ter pedido em namoro (CARDOSO, 2013, p.32), ou ainda a última festa de ano-novo de que a família participara (CARDOSO, 2013, p.29). Mas, em meio à rememoração, adiante está o presente, inescapável. O pai, Mário, corta com uma faca as dálias da toalha de mesa que a mãe bordara e, explicando à família tal violência diante da afetividade e do passado compartilhado, afirma "não fica cá nada. (...), nem o pó dos sapatos cá deixo, eles não 


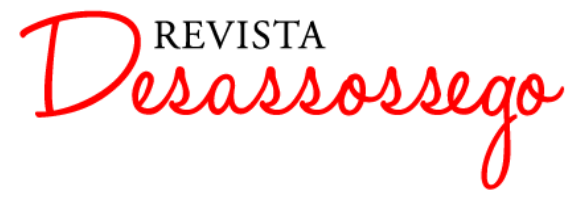

merecem nada" (CARDOSO, 2013, p.21). E Rui, também porque compartilha esse sentimento, traduz para si mesmo: “eles são os pretos” (CARDOSO, 2013, p.21).

Desde o desejo do pai de rasurar por inteiro todos os sinais da presença e da vida em Angola, optando por não deixar rastros, até o desejo ambíguo do jovem de conhecer a metrópole, manifesta-se uma dinâmica tensa. Rui constrói para si o imaginário de um país não só dado a encontros - "talvez o encontremos por lá, o pai diz que a metrópole não é grande, talvez seja fácil encontramo-nos todos" (CARDOSO, 2013, p.18) -, mas também à experiência particular e juvenil da beleza, "o que tenho é de conhecer as raparigas da metrópole, raparigas lindas com brincos de cereja e sapatos de bailarina" (CARDOSO, 2013, p.19). E que é, além de tudo, a figura de um novo e possível pertencimento que Angola não mais representa. Mas esse momento de desejo e, todavia, de perda, misto de invenção, de apagamento e de rememoração é propriamente agônico, porque torna a vontade imaginária para o adolescente narrador.

E a memória, a rememoração agônica, é muito bem formalizada quando lá chega a família. O teor - conceito que, para dizer com Benjamin (2013, p.13), compreende essa área na qual a forma e o conteúdo convergem e convivem -, ele condensa-se então. As frases, ao final de cada parágrafo, sem sentido na sequência disposta, se consideradas juntas, montam fora da ordem cronológica a cena em que o pai fora sequestrado pelos soldados e caracterizam-se pelo bloqueio das associações, característico do trauma. Verdadeiros flashes, num tipo de agenciamento estilístico que percorre o romance, dão ideia de sua construção geral - a justaposição se insere como força central organizadora dos parágrafos, das personagens, dos ambientes e das situações que se vão tornando cada vez mais ambíguos à medida que o texto avança. Dimensionam-no como esse momento em que o passado move o presente, ainda que a contrapelo, e que revolve a vontade. $\mathrm{E}$ a ambiguidade, enquanto força composicional, produz-se acumulativamente por essas justaposições.

Assim, reelaborando a cena, tem-se: “o jipe desaparece depois da casa da Editinha", “as mãos do pai amarradas atrás das costas", "Vámo matáti cum tuá arma e tua bala”, "a poeira demora a assentar", "a balalaica do pai ensopada de sangue”, “o isqueiro Ronson Varaflame caído o pé do canteiro", "a mãe de braços caídos no fim da rua”, "o sangue do pai no asfalto", "a minha irmã sem conseguir descer as escadas", "a Pirata a ganir com o pontapé do preto", "os olhos aflitos do pai”, "os pretos a rirem quando o jipe arranca”, "a 
arma do pai nas mãos do preto", “a arma do pai apontada à cabeça" e " a mãe a correr por dentro da poeira que não assenta" (CARDOSO, 2013, p.59-63).

No entanto, aquele desejo imaginário de Rui é logo denegado pela realidade. Ao fim só há a estagnação de um presente sem perspectivas, em que mesmo as jovens que o encantavam na imaginação "não valem nada" (CARDOSO, 2013, p. 230). Se o motivo das raparigas com brincos de cereja dissolve-se pouco a pouco nesse novo lugar, é o tema da casa que adquire maior importância para Rui e para sua família, ao longo do romance. Está em questão a acomodação deles a esse espaço neutro que é o hotel, "um quarto pode ser uma casa e este quarto e esta varanda de onde se vê o mar é a nossa casa. A mãe e a minha irmã não pensam assim e por isso se estamos na rua nunca dizem, vamos para casa. Dizem sempre, vamos para o hotel” (CARDOSO, 2013, p.163). Com a mesma intensidade, há a procura por resolver essa presença-ausência do pai - "não precisamos de combinar que faríamos segredo sobre o que aconteceu ao pai” (CARDOSO, 2013, p.76), ou então "repito as palavras que o pai costuma dizer e peço à mãe que coma, não temos raízes no chão, (...), as palavras do pai sem o pai no restaurante do hotel” (CARDOSO, 2013, p.87) e a tentativa de compreender essa nova posição: "agora somos retornados. Não sabemos bem o que é ser retornado mas nós somos isso" (CARDOSO, 2013, p. 77).

Diante desses tempos conturbados, da lenta e progressiva perda dos laços afetivos e de pertencimento, é que se engendra a angústia, e é sempre aí, nesse lugar por demais mutável, que a vontade tenta se firmar.

Mas é preciso atentar às escolhas de Rui nessa topografia movediça. É ele mesmo quem se coloca a questão do aprendizado: "Ensinaram-nos tantas coisas sobre a metrópole, os rios, as linhas de caminho-de-ferro e só não nos ensinam o mais importante, que a metrópole muda as pessoas" (CARDOSO, 2013, p.192), e o que essa mudança indica também é a necessidade, ou antes o desejo, que progressivamente se lhe torna claro, de transgredir.

Por um lado, premeditando o roubo dos contêineres de outras famílias, mortas durante a o processo de descolonização, ao ver um limite que a ele e a sua comunidade não se afigura de modo nenhum trespassável, procura justificar-se:

O que é difícil é manter o pensamento de roubar (...). Sei que é assim que se pensa porque já pensei da mesma maneira e teria continuado se não tivesse a mãe e a minha irmã para levar apara a América. Mas tenho e isso é mais importante do que pôr-me a pensar no que está certo ou errado, (...) (CARDOSO, 2013, p.198). 
Apesar de o plano não se concluir, devido à volta do pai, por si ele já atormentava o rapaz, que chegara mesmo a sonhar que "os mortos de Sanza Pombo estavam zangados" (CARDOSO, 2013, p.197) consigo.

Bataille (2014), apesar de tratar especificamente do erotismo, considera que toda transgressão, ao mesmo tempo em que se opõe a um interdito, procura superá-lo. Mas pode-se pensar também, a partir dessa generalização, em outra forma de experiência da transgressão, menor em grau e em qualidade e na qual a dimensão do sagrado, apesar de existir, evade-se. Pois, sendo em última instância o dado de um acordo social, é possível afirmar com o filósofo francês que "podemos chegar à proposição absurda: 'o interdito está aí para ser violado”" (BATAILLE, 2014, p.88).

Em O Retorno, não se pode dizer que a angústia e a transgressão são apenas inconscientes, mas correspondem a uma convergência de fluxos e de intensidades, às vezes francamente opostos entre si, que vão lhes configurar uma forma transitória, movediça, feita de choques, agônica. Porque as ações de Rui na narração debatem-se entre as possíveis escolhas e a espera, entre o desejo e a realidade, entre a perda da casa e a necessidade de pertencimento, entre a perda do pai e a manutenção da família. As transgressões, portanto, apesar de faces ativas dessa vontade condicionada e angustiada que, do contrário, seria inerte, são linhas de fuga e ao mesmo tempo movimentos irrefletidos de enfrentamento. As transgressões de Rui aparecem como os desvios que se lhe mostram possíveis - enquanto figura singular do estar-desterrado - diante da precariedade do real, da falta de afetividade e de horizontes, sempre à margem.

\section{Eu estive aqui}

Porém o pai retorna. E é sobretudo a essa volta da morte, a essa anábase que o título também parece se referir e que por si só é bastante problemática. A dinâmica do romance, que até então se organizava ao redor de temas como o silêncio, a solidão, a perda e a ausência, é subitamente quebrada por um movimento que, aos olhos do leitor, é completamente exterior, como uma intromissão. E sua condição problemática está presente no próprio texto, quando o pai é reintroduzido ao enredo, e Rui pensa "ninguém volta da morte mas o pai está à porta do nosso quarto" (CARDOSO, 2013, p. 220). Mas 
esse teor permanece, entretanto, passando a um plano de fundo conquanto os paradoxos do personagem se atenuam nas sequências seguintes.

Mas, de volta no que concerne à agonia, processo que destacamos até aqui, há uma cena preciosa em que Rui confronta sua professora de matemática em Lisboa, porque ela o chamara de "retornado":

Sundu ia maié, sundu ia maié, puta que a pariu. Vou dar pontapés em todas as portas até chegar ao pátio do recreio, a puta da professora mandou-me para a rua com uma falta a vermelho mas eu vingo-me, quero lá saber que as contínuas refilem, ó menino isto aqui não é a selva, não é como lá de onde vens, aqui há regras, sundu ia maié, estamos a avisar-te menino, abro o peito e dou um pontapé noutra porta, conhecem-me de algum lado, olho as velhas bem de frente para lhes mostrar que não tenho medo, abro as narinas como o Pacaça diz que todos os animais fazem antes de atacar, as velhas recuam com as batas cinzentas e enfiadas nas meias elásticas, lá podias andar montado nos leões mas aqui tens de ter modos, as velhas refilam mas nem tentam impedir-me, têm medo de mim, passo pela cantina e dou um murro no carro dos tabuleiros, só me falta bater com a mão no peito para verem que acompanhava mais com os macacos do que com os leões, as velhas até saltam com o estrondo que o carro dos tabuleiros fez, se querem dizer mal dos retornados vou thes dar motivos, sundu ia maié (CARDOSO, 2013, p.139).

Esta violenta afirmação de Rui em quimbundo é, portanto, afirmação do Rui angolano. É, por isso mesmo, reativa e demarcativa. Ao afirmar-se com a linguagem daqueles que ele antes chamou de pretos, quando reforçava a visão racista do pai e da comunidade portuguesa, ele se denuncia como diferente e periférico num lugar onde, em seu imaginário, achara que pertenceria ao centro. E essa nossa leitura evoca as pesquisas que vem fazendo Margarida Calafate Ribeiro (2004) acerca do estatuto cultural e simbólico de Portugal.

$\mathrm{Na}$ dinâmica de personagem agônico, ora ele responde às classificações esquemáticas de uma sociedade em turbulência que, por outros modos, transpõe a dinâmica hierárquica colonizado-colonizador definida também como preto-branco ou como selvagem-civilizado, ora ele se põe no lugar que antes, em Angola, teria desmerecido e subordinado.

Após o desterramento, a migração, Rui sente-se periférico em Portugal - justo o contrário do que havia sido até então. E de explorador ele passa a explorado numa sociedade que replica as formas da colonização. Desterrado em sua terra, ele agora é desterrado em todas as terras e sonha a todo momento com uma viagem para a América, mesmo após a chegada do pai, “(...) mas agora é o pai que vai levar-nos para a América, o 


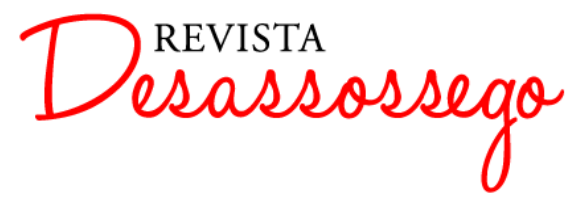

pai não pode querer ficar aqui" (CARDOSO, 2013, p.230), expandindo seu desejo em busca de um outro imaginário.

Por outro lado, a professora portuguesa, identificada com a opinião pública em Portugal, chamando aos portugueses exilados e a seus filhos "retornados", afirma-os imperialistas, exploradores, antidemocratas, conservadores e estabelece uma distinção profunda que era a mesma de Portugal durante a Revolução dos Cravos: os que chegaram da colônia eram tidos como o braço salazarista do recém-finado Império, resquícios de um tempo sombrio, autoritário, fascista e embrutecido. Ela os condena e acaba, também, por replicar a linguagem daquilo que condena, a colonização. Explicita, como personagem secundária, uma visão partilhada por vários outros: o professor de Angola que queimou $O s$ Lusiadas, o Tio Zé, as mulheres que recusam a toalha de mesa feita pela mãe... Mas, com a professora, o problema da língua e da linguagem se acentua, faz lembrar a frase de Rui, "se falássemos todos a mesma língua era mais fácil entendermo-nos” (CARDOSO, 2013, p.195). O mito do lusitanismo ainda resiste.

O livro, entretanto, vai em outro sentido e discute a negação da possibilidade de uma comunidade, formada em distinções identitárias tão marcadas, integrar-se. O misturar harmônico e afetuoso, difundido pelo lusotropicalismo, é aqui uma interdição e um desterramento. Do mesmo modo que os angolanos acabam por rejeitar a comunidade portuguesa e depois travar entre si guerras terríveis, também os portugueses rejeitam simbólica e praticamente os portugueses-angolanos sob a alcunha de retornados.

O dissolver de toda possibilidade de integração se dá por muitas formas, pessoais e coletivas, na ruína prática e na dissolução simbólica do sonho imperial. Mostra, sobretudo, que a diferença não é uma simples síntese nova, mas também uma interdição. E nisso converge toda uma linhagem do pensamento contemporâneo (autores como Jean-Luc Nancy, Maurice Blanchot, Toni Negri, Paolo Virni e Giorgio Agamben). Ela demonstra como certas formas do passado que pareciam garantir um contorno uníssono e certa consistência ao laço social e aos modos de associação entraram em colapso. E se antes o comum era tomado como um espaço abstrato capaz de conjugar individualidades e de se sobrepor a todos os grupos, percebe-se a emergência de forças de afetação, elaborações que, como diz Paolo Virno, postulam o comum mais como premissa do que como promessa. 


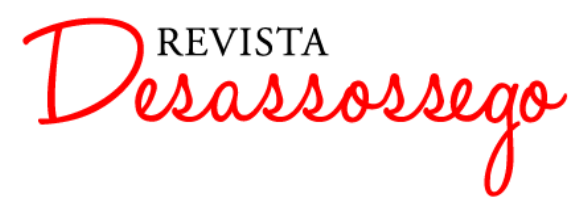

Também por isso, apesar de todas as perspectivas que cortam o romance - o comunismo, o racismo e a homofobia, o capitalismo mais atroz, a glorificação do colonizado e do colonizador - sob o enquadramento de diversos personagens - o Pacaça, o José Comunista, a diretora do hotel, o Tio Zé, o pai Mário, Rui -, não há, ao fim, harmonia ou consenso.

A comunidade, assim, pode ser pensada mais como uma chave não fusional, não totalitária, não unitária. Retirada a pátina nostálgica do refrão "lá onde há sociedade, perdeu-se a comunidade", é possível ver interpenetradas, e às vezes dissonantes, formas de copertinência, de comunhão e de dissimetria.

Todas as perspectivas, as vozes que o romance contém, vale dizer, são formas do testemunho de um tempo, ainda que parciais, são afirmações de uma memória. As mudanças que Rui carrega (a espera, o desterro, a migração) alteram substantivamente a ligação do personagem principal com a comunidade, com o comum e com o familiar, assim como estes passam a se relacionar de outra maneira com ele.

Este romance, que erra por territórios oblíquos, cujo desenho incorpora o mais íntimo e, ao mesmo tempo, o coletivo, o nacional, faz reverberar a frase de Franny citada por Deleuze: "Estou na borda desta multidão, na periferia; mas pertenço a ela, a ela estou ligado por uma extremidade de meu corpo, uma mão ou um pé” (DELEUZE, 2011, p.55).

Nem fora, nem dentro. Nem centro, nem margem. Periferia. Se a impossibilidade de voltar para casa deixa de ser problematizada por Rui, no desfecho do romance, algo surge, diverso do combate: a vontade de escrita, o desejo de deixar alguma forma de registro testemunhal: eu estive aqui. Fazer falar as cicatrizes.

\section{REFERÊNCIAS BIBLIOGRÁFICAS}

ARNAUT, Ana Paula. (Estereó) "Tipos (Post-)Coloniais: O Retorno (Dulce Maria Cardoso) e Caderno de Memórias Coloniais (Isabela Figueiredo)". Revista de Estudos Literários. Personagem e Figuração. Coordenação Carlos Reis, Marisa das Neves Henriques. Coimbra: 2014.

BAILLY, Anatole et al. Dictionnaire Grec-Français. Paris: Ed. Hachette, 2000.

BATAILLE, Georges. O erotismo. Trad. Fernando Scheibe. Belo Horizonte: Ed. Autêntica, 2014.

BENJAMIN, Walter. Escritos sobre mito e linguagem. Trad. de Susana Kampff Lages e Ernani Chaves. São Paulo: Duas Cidades: Ed. 34, 2013.

CARDOSO, Dulce Maria. O retorno. Rio de Janeiro: Ed. Tinta-da-China, 2013.

DELEUZE, Gilles; GUATTARI, Félix. Mil Platôs: capitalismo e esquizofrenia 2. Vol. 1. Trad. de Ana Lúcia de Oliveira, Aurélio Guerra Neto e Célia Pinto Costa. São Paulo: Ed. 34, 2011. 
FIGUEIREDO, Isabela. Caderno de Memórias Coloniais. Lisboa: Editorial Caminho, 2015.

HOUAISS, Antônio; VILLAR, Mauro de Salles. Dicionário Honaiss da língua portuguesa. Rio de Janeiro: Ed. Objetiva, 2009.

LOURENÇO, Eduardo. Do colonialismo como nosso impensado. Organização e prefácio Margarida Calafate Ribeiro e Roberto Vecchi. Lisboa: Gradiva, 2014.

MACEDO, Helder. Camões e a viagem iniciática. Rio de Janeiro: Mobile, 2011.

MIRANDA, Sá de. Poesia e teatro. Seleção, introdução e notas por Silvério Augusto Benedito. Lisboa: Biblioteca Ulisseia de Autores Portugueses, 1989.

RIBEIRO, Margarida Calafate. Uma história de regressos. Império, Guerra Colonial e Imperialismo. Porto: Edições Afrontamento, 2004.

VERNANT, Jean-Pierre. Esboços da vontade na tragédia antiga. In: VERNANT, JeanPierre; VIDAL-NAQUET, Pierre. Mito e tragédia na Grécia antiga. Trad. de Anna Lia A. de Almeida Prado. São Paulo: Ed. Perspectiva, 2014. 